\title{
From Margin to Mainstream: Retranslation of Early Chinese History
}

\section{Yuan TAO*}

This paper sets out to examine the diachronic movement of the three English versions of Zuozhuan 左傳 (Commentary of Zuo) by James Legge ([1872] 1991), Burton Watson (1989), and Stephen Durrant, Wai-yee Li, and David Schaberg (2016) with the time span of nearly one century and a half based on paratextual analysis. Zuozhuan, listed as one of the thirteen 'Chinese canons,' is the core Confucian narrative history recording the turbulent period in the preQin dynasty between 722-468 BCE. The current literature often involves the examination of its narrative, key words interpretation, and comparative study with other historiographies; however, there has been little discussion about the English translations of the historical texts. Drawing on Lawrence Venuti's retranslation theory, the present study explores the retranslation of Zuozhuan in terms of the translators' agency, the intertextual relationship with the other historiographies, and the role of history. Our results indicate that Legge explores the comparative and the scholarly value from the Victorian moral standard and Protestant ideology. Watson, by contrast, places priority on its narrative feature in the late twentieth century. Durrant et al. highlight literariness and the scholarly and the pragmatic value at the start of the new millennium. The research reveals the translators' endeavor to change the status of early Chinese history from periphery to centrality through literary features and easier accessibility while preserving the academic value. This research not only sheds new light on the cause and value of the retranslations but also investigates the application of the retranslation hypothesis on the newly-targeted data of the historical canon.

Keywords: retranslation; agent; intertextuality; historical moment; paratextual; Zuozhuan

\section{Introduction}

Texts of canonical status or pragmatic function are often retranslated simultaneously or

\footnotetext{
* Associate professor at Dalian University of Technology.

E-mail: taoyuan@dlut.edu.cn; ORCID ID: https://orcid.org/0000-0002-7301-6535.

(Received 15 April 2020; accepted 9 June 2020)
} 
transLogos 2020 Vol 3 Issue 1

over a period of time. The (re)translations on the same source text, either by design or accident, might diversify significantly in terms of the lexical, grammatical, thematic, and even the ideological level (Deane-Cox 2014, 14-16). A number of researchers (e.g., Meschonnic 2011, 59) have reported the change generated by retranslation, which helps produce a variety of versions adapted to the latest social and cultural norms. Central to the entire field of retranslation is the theoretical research on the relationship between the source text and various versions, in particular, the retranslation hypothesis (Bywood 2019; Desmidt 2009; Koskinen and Paloposki 2015) and the factors influencing retranslation (Deane-Cox 2014, 14-16; Van Poucke 2017; Venuti [2003] 2013). Moreover, recent trends in retranslation have led to the empirical study on literary works and audiovisual productions of novels, children's work, movies, TV series, and songs in terms of the ideology, social situation, norms, and intertextual relations (Brownlie 2006; Di Giovanni 2017; Greenall 2015; Kujamäki 2001; Zhang and Ma 2018).

Though retranslation has been the leitmotif in translation studies in the past three decades, the translation of historiography has occupied a marginal status despite its canonical status and far-reaching influence in literature and history. Such is the case with Zuozhuan 左傳 (Commentary of Zuo), one of the earliest historical narratives in China, chronicling the turbulent and transitional period when the feudal kingdoms strived for hegemony between 722 468 BCE. Listed as one of the thirteen canons of Confucian classics, the book was compiled to record the Confucian morality, the politics, and the military and diplomatic affairs in pre-Qin China. The landmark historical canon has been translated into English three times by James Legge ([1872] 1991), Burton Watson (1989), and Stephen Durrant, Wai-yee Li, and David Schaberg (2016) over a period from the Victorian era to the start of the new millennium. Although extensive research to date has been carried out to elaborate on its narrative, to interpret the key words of 'heaven' and 'ritual propriety,' or to perform comparative study with the other historiographies (Brooks 2003; Li 2014; Pines 2002; Schaberg 2002; Wang 1977), far too little attention has been paid to any systematic research in the retranslation of this historiography. 
This article therefore aims to map the trajectory of the (re)translations of Zuozhuan over a period of one century and a half based on the theoretical framework of retranslation by Lawrence Venuti ([2003] 2013). Three factors are taken into consideration in the retranslations: the translators' agency, the intertextuality with the source text and the target text, and the influence of history. By agency, I focus on the factors involved with the translators' power, such as their awareness of previous versions, their purposes, and influences of the translations; the intertextuality is the complicated relationship between the English versions and the other historiographies in source and target cultures; the impact of the historical period is the historical background and the corresponding strategies of translation. Ultimately, the research, by the case study of the translation of Zuozhuan, seeks to explore the causes of the retranslation and the value created in the (re)translation and testify the retranslation hypothesis through the diachronic and empirical study on the retranslation of historiography.

The study provides an exciting opportunity to advance our knowledge of retranslation theory with three important areas which this study makes an original contribution to. First, it explores the motivations of the translators in light of the marginal status and the obscure content of historical classics. Second, it delves into the value of each version and the translators' effort to integrate early Chinese history into world history on the basis of the diachronic movement. Third, the research illustrates the retranslation hypothesis in the newly-targeted area of historiography.

The remainder of the paper is structured as follows: It reviews the previous research on retranslation, and particularly, Venuti's framework of retranslation in the second section. The section also investigates the manifold roles which paratext plays in translation. The third section introduces the methodology and the paratextual elements collected in the study. It subsequently explores the diachronic movement of the three versions by analyzing the agency, intertextuality, and influence of historical moments on the basis of the paratextual analysis. The foregoing discussion elaborates on the values of each version and the diachronic movement, which shed new light on the retranslation hypothesis on the translation of historiography. Finally, the sixth 
transLogos 2020 Vol 3 Issue 1

Tao, Yuan, pp. 1-23

A Translation Studies Journal

From Margin to Mainstream:

Retranslation of Early Chinese History

(C) Diye Global Communications diye.com.tr|diye@diye.com.tr

section concludes the discovery in the research, by also presenting the limitations as well as suggestions on future study.

\section{Literature Review}

\subsection{Previous Research on Retranslation}

Retranslation, simply put, refers to "different versions, in this case translational versions of one source text into the same language, usually over a certain time period" (Brownlie 2006, 146). Since it is involved with various target texts on the same source text, more recently, literature has emerged that offers contradictory findings about the relationship between the (re)translated versions and the source texts. Although the retranslation hypothesis (Bensimon 1990; Berman 1990) claims that later versions tend to recover the features of the source text, debate continues about whether the proposal is applicable to all texts. Through the translation of children's books, Isabelle Desmidt (2009) argues that retranslation is related to the text type, and the hypothesis may not be applicable to all the text types. The idea is backed up by Lindsay Bywood (2019) who claims that the proposal does not apply in audiovisual corpus based on her analysis of subtitles from German to English. Contrary to the prevailing view that the first version is the raw material for improvement, Kaisa Koskinen and Outi Paloposki (2015) highlight the influence of the first translation on later versions in reputation and poetics on the basis of poetry translation.

Furthermore, much of the recent literature pays particular attention to the causes of retranslation. Piet van Poucke (2017) argues that linguistic, translational, and cultural aging (i.e., outdated linguistic features, the development in translation conventions, and readers' appreciation) may bring about retranslation of literary works. Henri Meschonnic (2011) proposes that translators strive for a change in the new versions (59). Likewise, Sharon DeaneCox (2014) observes that the translators aim at challenge, dialogue, and "a more elaborate model" (10). 
Aside from the change, or "appreciable difference" designed by the translator, Venuti ([2003] 2013) is more concerned with the value doubly created in both the receiving culture and the previous versions based on the retranslation of canonical works (96-100). He further manifests that the created value is intertwined with three factors in translation: The first is the agency of the translators (i.e., their awareness of the previous versions, intentionality, and the influence of their translations). The second is the intertextual relationship with both the source text and the text constructed in the target culture. Both agency and intertextuality lead to the third factor: the role of history which influences the translators' approaches for the reception in the target culture in a specific historical period.

\subsection{The Function of Paratext in Translation}

Gérard Genette (1997) defines paratext as "the fringe, always the conveyor of a commentary that is authorial or more or less legitimated by the author, constitut[ing] a zone between text and off-text" (1). It acts as the invitation for the readers with the materials explanatory, supplementary, or commentary inside or outside of the core text. Genette further classifies paratext into various subcategories according to the spatial location, temporal situation, the discourses, the sender, and the addressee, which present the authorial and/or allographic introduction for the readers.

Placing literary works as the focus, Genette did not incorporate translation into paratext, whereas many scholars have elaborated paratextual functions inside and outside the translated text since the coinage of the concept. To start with, paratexts are considered as "mediators between the text and the reader [having] potential influence on the reader's reading and reception of the works" (Kovala 1996, 120). In other words, paratexts exert illocutionary force ${ }^{1}$ on the readers. Furthermore, they serve the "functions of explaining, defining, instructing, or supporting, adding background information, or the relevant opinions and attitudes of scholars,

\footnotetext{
1 Proposed by British philosopher John Langshaw Austin (1962), illocutionary force denotes the performative or imperative of an utterance which "will often, or even normally, produce certain consequential effects upon the feelings, thoughts, or actions of the audience" (101).
} 
translators and reviewers" (Pellatt 2013, 1). Paratextual elements, albeit peripheral to the core text, can be considered a main source of information concerning the intention, commentary, and historical background, to name just a few. In light of the multiple functions, the article applies the paratextual analysis in the retranslation of historiography to explore the agency, intertextuality, and the influence of the historical moments.

\section{Methodology}

This paper follows a case-study design, with an in-depth and diachronic study involving the comparison of the three English versions of Zuozhuan by Legge ([1872] 1991), Watson (1989), and Durrant et al. (2016). The study examines the three translations paratextually on the basis of two subcategories. The first is the peritext in the translated texts including the title, epigraphs, preface, intertitles, footnotes, and the brief introductions between the entries. Located inside the text, peritext brings to light the intention, elaboration, and guide of the translators implicitly or explicitly. The second is the epitext which is external to the translation and includes the interviews, diaries, biographies, and the other articles and essays by the translators related to Zuozhuan. External to the text per se, epitext manifests the translators' motivations, interpretation, and commentary beyond the limitation of the space. Overall, the research examines paratextually the translators' agency, intertextual network, and historical background in the retranslation.

\section{On the Retranslation of Zuozhuan}

Listed as the top one among the three commentaries appended to Spring and Autumn Annals (hereafter called simply The Annals), Zuozhuan was named after the writer Zuo Qiuming, a historiographer contemporary with Confucius. It records 254 years of chaos in the pre-Qin dynasty on the detailed year-by-year and month-by-month account of the historical events alongside the author's commentary of Confucian morality. Hence the book has been held in high regard in history, ideology, and society, setting the precedent of format and expressions 
transLogos 2020 Vol 3 Issue 1

Tao, Yuan, pp. 1-23

A Translation Studies Journa

From Margin to Mainstream:

Retranslation of Early Chinese History

(C) Diye Global Communications diye.com.tr|diye@diye.com.tr

for the historical and literary works to follow.

The Chinese historical canon has been translated into English three times by Legge,

Watson, and Durrant et al. The major paratextual elements are illustrated in table 1.

Table 1. Paratexts of the three English versions of Zuozhuan

\begin{tabular}{|c|c|c|c|}
\hline & $\begin{array}{l}\text { Legge's } \\
\text { version }\end{array}$ & $\begin{array}{l}\text { Watson's } \\
\text { version } \\
\end{array}$ & $\begin{array}{c}\text { Durrant et al.'s } \\
\text { version }\end{array}$ \\
\hline Title & $\begin{array}{l}\text { The Ch'un Ts'ew with } \\
\text { the Tso Chuen }\end{array}$ & $\begin{array}{l}\text { The Tso Chuan: } \\
\text { Selections from China's } \\
\text { Oldest Narrative History }\end{array}$ & $\begin{array}{l}\text { Zuo Tradition } \\
\text { (Zuozhuan) }\end{array}$ \\
\hline Base text & $\begin{array}{l}13 \text { classics by Ruan } \\
\text { Yuan }\end{array}$ & $\begin{array}{l}\text { Shen Yucheng, Kaizuka } \\
\text { Shigeki }\end{array}$ & $\begin{array}{l}13 \text { classics by Ruan } \\
\text { Yuan }\end{array}$ \\
\hline $\begin{array}{l}\text { Date of } \\
\text { publication }\end{array}$ & {$[1872] 1991$} & 1989 & 2016 \\
\hline Paratexts & $\begin{array}{l}\text { Prolegomena, notes, } \\
\text { commentary, indexes } \\
\text { of proper names }\end{array}$ & $\begin{array}{l}\text { Introduction, notes, table } \\
\text { and map of states, index } \\
\text { of subjects }\end{array}$ & $\begin{array}{l}\text { Chronology, maps, } \\
\text { introduction, notes, } \\
\text { commentary, } \\
\text { bibliography, index of } \\
\text { proper names }\end{array}$ \\
\hline Publisher & SMC Publishing & $\begin{array}{l}\text { Columbia University } \\
\text { Press }\end{array}$ & $\begin{array}{l}\text { University of } \\
\text { Washington Press }\end{array}$ \\
\hline
\end{tabular}

As indicated in table 1, the paratextual elements present an overview of the translator's interpretation, influence, and intention through the titles, introductions, notes, publishers, and so forth. It is noticeable that the translators of later versions apply more paratextual elements than the predecessors, meaning that they provide more introductory information for the reception among the target readers. The paper will elaborate the three versions paratextually from the three perspectives of agency, intertextuality, and the role of history.

\subsection{Agency}

Originated from sociology, agency is denoted as "a flow of intentional action" which is 
involved with the agents' motivation, reflective monitoring, rationalization, and "the transformative capacity" or power (Giddens 1986, 8-15). Inspired by Anthony Giddens, Venuti applies the concept into translation, which he regards as an intended action for preserving or challenging the present norm. He agrees with Giddens in the aspect that agency is "the ensemble of motivations, conditions, and consequences that decisively inform the work of translating and allow it to produce far-reaching social effects" (Venuti [2003] 2013, 97). In particular, he emphasizes the "intentionality ... to make an appreciable difference" (100) according to the translation norms or ideology. In this article, agency is applied to describe the translators' awareness of previous translations, their motivations, and the influence of their translation.

\subsubsection{Legge's Intention for Comprehension, Comparison, and Scholarly Value. As a Scottish} Congregationalist, Legge set his heart to China and started his translation of The Chinese Classics encompassing the most representative Confucian works since his arrival in Hong Kong in 1843. After staying here for three decades, he returned to the United Kingdom and became the first professor of Chinese at the University of Oxford.

Though Legge's translation is the first English version of Zuozhuan, it is argued that the book is not the first European version. Emil Bretschneider claimed that The Annals was translated into Russian by "Father Daniel, of the Russian Ecclesiastical Mission" but not published, and the first book of The Annals was translated into Latin by Gottlieb S. Bayer and published in the "“Commentaria Academiae Petropolitanae' [Essay series of Academy of Saint Petersburg] vol. 7" (Legge [1872] 1991, 147). However, Legge stated that he had never encountered the above-mentioned versions, indicating that he set the precedent in the English translation of Zuozhuan.

Legge's translation of the Confucian historiography served three purposes of comprehension, comparison, and scholarly value. First of all, Legge (1905) believed that the premise to understand China, a mysterious land to then Europeans, was to know its classical literature as "he should not be able to consider himself qualified for the duties of his position until he had mastered the Classical Books of the Chinese, and had investigated for himself the 
whole field of thought through which the Sages of China had ranged" (29).

Second, Legge adopted a comparative approach between Confucianism and Christianity in terms of ideology and historiography. He aimed at converting the Chinese because of his identity as a missionary. Rigorously trained in classical languages and moral philosophy, he believed the historian's responsibility was to convey the truth. Through the comparison, Legge ([1872] 1991) intended to convince the readers of the inadequacy of Confucius, therefore guiding the readers to "another Teacher" (53) for his lifelong purpose.

Last but not least, Legge gave priority to the scholarly value of his translation because of his meticulous education in Latin and history. He translated faithfully for "the important service to students of Chinese literature and to his readers generally" rather than "paraphrase, which he considers a slovenly and unscholarly practice" (Legge [1872] 1991, v-vi). Legge's translation is characterized by the lengthy notes and commentaries for the "hundredth" reader who will not find his annotation "a bit too long" (Legge 1905, 42). His elaboration of the background knowledge strives for the "philosophical, historical and philological" values (Girardot 2002, 62). It was from the training of Latin that he began to "cultivate his scholastic talents until he entered the Latin classes at the Huntly parish school at the age of twelve" (26). The classical Latin texts by names such as Horace, Virgil, and Ovid and especially the works of George Buchanan (1506-1582), including Rerum Scoticarum Historia (The history of Scotland), started "Legge's first primer in translation and philological method" (27).

The translation was included into the fifth volume of The Chinese Classics, which covered the Confucian works of Four Books and Five Classics and made Legge the first winner of the Prix Stanislas Julien in Paris in 1875. Because of its prestigious and authoritative status, the book established the standard for later translators, particularly through its paratextual elements.

\subsubsection{Watson's Attempt at a Popular Narrative for General Readers. Watson was an American} sinologist well-known for his translation of Chinese history and poetry. He joined the United States Navy in 1943 and set foot on Japan in 1945, starting the first encounter with East Asia. 
From 1946, he majored in Chinese and Japanese Studies at Columbia University on the G. I. Bill, as he was devoted to the study of Oriental classics. He moved to Japan in 1973 and stayed there for the rest of his life. He was awarded the PEN Translation Prize twice for his translation of poetry, the Gold Medal Award of the Translation Center at Columbia University, and the PEN/Ralph Manheim Medal for Translation for his lifetime achievement.

As the second English translator of Zuozhuan, Watson was fully aware of the complete version by Legge; however, he was discontented with Legge's version for two reasons. The first was Legge's judgment of Zuozhuan as a version "relegated to the notes" of The Annals, resulting in his inconvenient typography with very small fonts intermixed with the translator's personal notes and comments (Watson 1989, xxxvii). Another dissatisfaction of Watson lay in the obsolete language of over a century ago because of Legge's lexicon and fidelity to the source text.

By contrast, Watson strived for a more simplified and readable version for general readers with selected anecdotes accompanied by paratextual elements and clear-cut themes of conflict. His target readers were those "who do not feel inclined to work their way through the entire text but wish to familiarize themselves with its most famous and influential narratives and get some sense of its style and principal ideas" (Watson 1989, xxxv). For simplicity, he selected the most household anecdotes in the source text rather than the complete text, rendering them into thirty-seven chapters in the target text. To facilitate the reading, Watson put introduction before each chapter and explained the parts he omitted in the transitional passages, thus stringing together the anecdotes with paratextual elements.

Moreover, Watson foregrounded readability with narrative and the distinct theme of conflicts among the feudal states. He insisted that "translations not only be accurate in meaning but in an English style that was pleasing and unlabored" under the influence of his teacher Chichen Wang at Columbia University (Balcom 2005, 8). To this end, he abandoned the chronological organization of the source text and rearranged it into a collection of anecdotes. In addition, Watson illustrated the theme of each chapter with brief intertitles such as "The 
Battle of Han" and "An Inglorious Defeat for Sung," presenting the conflicts and themes succinctly. Accordingly, the Chinese chronicle was reframed into an intriguing narrative about the scramble over precedence and hegemony in early Chinese history.

The literary features enhanced both the version's popularity and its application. On the one hand, the book was published twice in 1989 and 1992, a remarkable achievement for a Chinese historical canon. On the other, "its high readability" enabled the translation to be selected "as the basic introduction to the Zuozhuan for undergraduate students throughout the Anglophone world" (Pines 2017, 290).

\subsubsection{Durrant, Li, and Schaberg's Version for a Broader Readership in the World. Durrant et} al.'s translation is a collaborate project by professors of Chinese Literature at American universities. Durrant is a professor emeritus of Chinese Literature at the University of Oregon, Li a professor of Chinese Literature at Harvard University, and Schaberg a professor of Asian Languages and Cultures at UCLA Center for Chinese Studies focusing on pre-Qin Chinese historiography and thought.

As the translators of the third version, Durrant et al. identified both the merits and the demerits of the predecessors' translations. First, despite acknowledgment of Legge's version as "a great sinological achievement," "a standard source for students of early China," and "a measuring rod" to the present, the translators concurred with Watson's view on the outdated Victorian prose and the format difficult for reading (Durrant et al. 2016, xxiv). As to Watson's abridgment, Durrant (1992) raises the question of "stylistic nuances" in the collapse of narrative time and the translation of proper names such as personal names, ranks, and titles and doubts Watson's accuracy in some terms. Overall, he holds that Watson's version can be taken merely as "a brief, guide to the text" (41) in the conveyance of meaning.

Durrant et al. translated the Chinese historic canon in the twenty-first century for three reasons. To start with, the translators notified the contrast in Zuozhuan's status in the target culture, both canonical and underestimated at the same time, insisting that this historiography should enjoy the same status on a par with the contemporaneous works by "Herodotus, 
Thucydides, and the Deuteronomic historians" (Durrant et al. 2016, xvii). However, the book has "never gained a significant readership outside East Asia beyond a small number of earlyChina specialists" (xxiii) due to the broken storyline interrupted by chronological organization and the silent narrator in early Chinese history. It was the translators' intention to enhance the marginal status of the Chinese historical classic. Further, the translators endeavored to provide a version with readability so as to enlarge the readership from the sinologists, historians, and specialists to general readers. In an online interview by AsiaNow (2018), the translators state that "our goal is to make this difficult text accessible to a large audience, so that it could finally take its place among the core classics of world literature." Moreover, the translators find it necessary to update the latest academic research on The Annals and Zuozhuan in the new version since systematic research on pre-Qin history in China and abroad has gathered new insights in the historical materials, institutions, and customs over one and half a centuries.

Published by the University of Washington Press in 2016, the book is the winner of the 2018 AAS Patrick D. Hanan Book Prize for Translation. It is believed that the translation may challenge the dominance of Watson's version in undergraduate studies (Pines 2017, 290).

\subsection{Intertextual Relationship}

Based on poststructuralism, Venuti stresses translation's inscription and the intertextual relations with both the source text and the target text. For one thing, the intertextual relationship with the source text helps determine the directness and clarity of translation; for another, the intertextuality with the target text is conducive to the reception among the readers.

\subsubsection{Legge's Intertextuality with Chinese Historiography and Western Classics. Legge} establishes the intertextual relationship with both the authoritative historical documents in the source text and the Western classics in the target text. On the one hand, he cites fifty-seven Chinese works of references on various topics of geography, proper names, divinations, and astronomy from the Han dynasty to the late Qing dynasty through both authoritative and widelyaccepted research. The heavily annotated translation enhances its academic value and helps the 
readers understand early Chinese history.

On the other hand, Legge establishes the intertextuality between Chinese historiography and the Western counterparts and the Bible in the format and in the interpretation of the key words. To start with, he addresses the writer Zuo Qiuming as China's Froissart, the medieval French historian, for his chronological narrative and retains this format in his translation, placing equal footing between Chinese and French chronicles (Legge [1872] 1991, 31). Furthermore, as a missionary, he claims that The Annals is to Zuozhuan what "the headings or summaries of contents which are prefixed to the chapters" are to "the chapters themselves" (23). When elaborating the concepts of meng 盟 (covenant) and shiyue 誓約 (an agreement with an oath), Legge reminds the readers of "the account of Jacob and Laban's covenant, Genesis, xxxi" (5). As a result, the intertextual relationship with the Western classics presents a comparative view in both historiography and ideology.

\subsubsection{Watson's Intertextuality with Oriental Research and Western Historiography. Watson's} experience at Columbia University and in Japan contributes to his construction of intertextuality with the Oriental academic research in the source text and the literary features of Western historiography in the target culture. In the first place, Watson's translation is based on Kaizuka Shigeki's Japanese translation of 1970 and Shen Yucheng's modern Chinese translation of 1981, taking references of the notes by Kamata Tadashi and Yang Bojun. In other words, his translation is based on the latest interpretations of Chinese and Japanese scholars.

Moreover, Watson attempts to construct the historical texts "in easily readable form so that they could be read by English readers as one reads Herodotus, Thucydides, Polybius, or Livy" (Balcom 2005, 8), who are well-known for the literariness in historiography. Therefore, Watson (1989) presents the translation centering on the conflicts of succession for thrones and military actions for hegemony, underscoring the themes occurring "again and again in the narrative" (xxvii). Therefore, Watson constructs an easy-to-follow historical canon with literary features in the target text for wider reception among general readers. 


\subsubsection{Durrant, Li, and Schaberg's Intertextuality with Heterogeneous Resources. Compared} with the two predecessors, Durrant et al. establish an even more extensive intertextuality with the authoritative historiographies in the paratextual elements to establish its canonical status in the target culture. After a decade of herculean labor, the translators not only consult the annotations and discoveries on Zuozhuan by scholars from the Han dynasty to modern historians in China but also cite the research from overseas scholars such as Takezoe Koko, Bernhard Karlgren, and Yuri Pines. Moreover, they refer to ten previous translations by English, French, Chinese, and Japanese translators such as James Legge, Séraphin Couvreur, Burton Watson, and Teruo Takeuchi. The heterogeneous resources contribute to detailed historical data and various interpretations for early Chinese history.

More importantly, the translators construct historiography with Western tradition since Herodotus or Thucydides, who "repeatedly appear as guides or commentators throughout their narratives" (Durrant et al. 2016, xviii). With elaborate introductions about the historical background of the source text, general introduction before each chapter, navigational passages on the causality and interrelationship between the anecdotes, the translators provide instruction, guide, and explanation for the readers with an internationalized standard for the readers.

\subsection{The Role of History}

Translation is subject to various factors such as the necessity, the language, the press, and the market in different historical moments. Translations reflect "the cultural formation where they are produced, circulating in institutions where values are arranged hierarchically and undergo various developments over time" (Venuti [2003] 2013, 105-106). The role of history, therefore, determines the translators' corresponding strategies in the target culture in the historical moment.

\subsubsection{Legge's Confucian Classics Translation in the Victorian Era. Legge translated Zuozhuan} in 1872 during the Victorian era when the United Kingdom was in rapid expansion all over the world as 'the empire on which the sun never sets' after the industrial revolution. Meanwhile, 
the London Missionary Society, the Christian mission founded in 1795, expanded its missionary work to Hong Kong after the First Opium War. As a member of the society, Legge was assigned to work as the headmaster of Ying-Wa College in Hong Kong where he embarked on the translation of The Chinese Classics.

It was the morality in the Victorian era that promoted Legge's selection of the source text and translation strategy. In the first place, morality takes the predominant role in England of the Victorian era since moral principles are "part of the fabric of both novel theory and canonical formation" (Rosenthal 2017, 2). Legge found commonality between the traditional values in Confucianism and the morality in the Victorian era, specifically in terms of "the filial piety," "the significance of manners and propriety," etc. (Girardot 2002, 207).

Legge applies relevant translation strategies to ensure a permanent value in the target culture. For one thing, Legge provides exegetical textual research for the readers: a lengthy academic prolegomena, numbered passages as those in the Bible for easier accession, a multitude of references and annotations of Chinese historians, commentaries on previous notes, and an index of proper names. With the comprehensive and exegetical explanation, the translation reveals the ancient Chinese civilization, leaving a legacy of academic value for later versions. For another, Legge's version illustrates a comparative value between Chinese and Western classics in intertextuality by preserving the format in the Western counterparts and comparing the key words and the themes in Confucianism and Christianity.

4.3.2 Watson's Popularized Narrative in the Late 1980s. Watson's translation is credited with the rapid development of China Studies in the United States in the twentieth century. Since its establishment by John King Fairbank in the 1950s, China Studies has been an independent discipline separate from sinology in Europe, focusing the comprehensive research on both contemporary China and the history of China. The 1970s witnessed dramatic changes in China, including Richard Nixon's visit to the country in 1972, the establishment of Sino-American diplomatic relations in 1979, and the Reform and Open Policy, which sparked more interest for China in the United States. 
Because of the growing emphasis on Asia, especially East Asia in the United States, Watson's translation was published in 1989 by the Columbia University Press as part of the Translations from the Asian Classics Series. Watson (1989) views Zuozhuan as the "oldest work of narrative history" (xi) in Chinese history which exerts great influence on later works of literature, historiography, and ideology in China, Korea, and Japan.

To facilitate the reception of the historical canon, Watson highlights the narrative in his translation by depicting the pre-Qin period with a series of anecdotes of conflicts for thrones and hegemony instead of the chronological organization in the source text. To make the narrative more coherent, he omits the historical events irrelevant to the theme such as the natural disaster, diplomatic activities, didactic poems, and the author's commentary on Confucianism. Rather, each chapter centers on one theme or subject, presenting a complete event from the reason or background to the development, the climax, and the ending. As a result, the Confucian historical chronicle is adapted into a popular narrative of court intrigues and political conflict, providing a panorama of early Chinese history with the most household anecdotes.

\subsubsection{Durrant, Li, and Schaberg's Internationalized Version in the Early Twenty-First Century.} Durrant et al.'s translation was published in 2016 when globalization was even more prevalent at the turn of the century. China's accession to the World Trade Organization (WTO) in 2001 enabled its greater integration into the global economy, rising to the second economic entity and the "new engine of world growth" (Garnaut 2012, 1). After decades of economic reform, the country wielded more clout in world economy, politics, and culture. In the meantime, the Western academia continued its China studies in the systematic and professional tradition. The translators selected Zuozhuan as a fundamental historical canon which "deserves a place alongside other great histories from the ancient world, like those of Herodotus, Thucydides, and

the Deuteronomic historians, with which it is roughly contemporaneous" (Durrant et al. 2016, xvii).

With regard to the translation strategies, the translators strived for a more readable and accessible version for the readers of the world with literariness, scholarly investigation, and a 
more reader-friendly format. To start with, the translators foregrounded the storyline running through historiography in the introduction before each chapter. The conflict shifted from the strife between minor overlords at the outset to the major power struggles between the hegemonies of Jin, Qin, and Chu, and finally to the contest between the southern rival states of $\mathrm{Wu}$ and Chu. Further, the translators inherited the exegetical and scholarly tradition advanced by Legge; however, with even more heterogeneous resources home and abroad, they provided the readers with ample historical background and various interpretations. The publication by the academic press also indicates the scholarly investigation of the version. Finally, the translators provided a more reader-friendly format for references with a numerical order before each entry, helping the readers who are in need of information about the source text and the target text.

Overall, with the intention of incorporating early Chinese history in the mainstream of world history, the translation was designed with Western historical fashion. Instead of the silent chronicler of Chinese, the translators took the multiple roles of interpreter, navigator, and commentator in the translation, emulating the writers of Western historiography of antiquity, to integrate China's early history into world history as the ancient civilization in Greece, Rome, and Egypt.

\section{Discussion}

Previous studies have noted the factors influencing retranslation but have rarely approached the value in retranslation. The results of this study indicate that the values created in each version are subject to different historical moments. Legge's translation is characterized by the scholarly and the comparative value, which helps shape the framework of translating historical texts through paratextual elements. In contrast, Watson gives priority to the literary value and readability in his abridgment by focusing on conflicts within and between the feudal states. Durrant et al.'s version, while carrying on the scholarly tradition introduced by Legge, distinguishes itself in literary and pragmatic values. The finding is consistent with the idea of 
Koskinen and Paloposki (2015) who observe that the first translation sets the standards for later ones.

The diachronic movement in the values of each version further testifies the retranslation hypothesis in the newly-targeted text of historiography. However, the retranslation of early Chinese history indicates that the translators, while preserving the scholarly value and the historical truth of the source text, may not follow the format of the source text for the sake of wider reception, which does not fully support the retranslation hypothesis.

A possible explanation for this result might be that historical canons, as opposed to other literary or pragmatic works, are less well-known to the public in both source and target cultures despite their canonical status. It might be surmised that the top priority for the translators was to enlarge the readership from historians and specialists to mass audience. With this in view, the translators made explicit the storyline through introductions and explanations with paratextual elements, adding literariness and readability to the target text. This result corroborates the finding of Desmidt (2009), who suggests that the retranslation hypothesis may not be applied to all the texts, as mentioned in the literature review.

The research makes two main contributions to the literature on reasons for the retranslation theory. For one thing, the result suggests that later versions would remedy the deficiency of the previous versions. The translators manifested the factors neglected by the predecessors or offered new interpretations brought by the academic research. For instance, Watson and Durrant et al. noticed the inconvenient format of the first version; likewise, Durrant et al. compensated the incompleteness and inaccuracy of Watson's version. For another, the translators, in view of the marginalized status of history among general readers, attempted to enlarge the readership with more accessible versions of a reader-friendly format and explanatory and navigational introductions.

The implication of this research is the possible application of paratextual elements in the translation of historiography. Paratexts, with the manifold functions of mediation, introduction, and navigation, may be applied to clarify the complicated relationship between 
historical figures, the causality between the events, the historical background, and the cultural terminology. Translation of historiography, therefore, strives for scholarly value and larger readership with readability.

\section{Conclusion}

The study was designed to determine the motivations and values created in retranslation and the relationships between the source and the target texts. Through the paratextual analysis on the role that translators' agency, intertextuality, and history play in (re)translation, the present study provides evidence that the translators are motivated by the enlargement of readership with an accessible format and literariness while attaching importance to the academic value. The evidence from this study suggests that paratexts play an important part in the explanation and interpretation of the translators' intention within the context of the translation of historiography

This is the first investigation, to the best of my knowledge, into the relatively underresearched territory of how historiography is (re)translated. The research makes three contributions to the current literature on retranslation theory. Firstly, scholarly value has been given much importance in the retranslation of historiography although the values, subject to historical moments, are constantly in the process of renewal. All the translators maintain the scholarly value, though some apply added value of comparison or literariness in the target text. Secondly, the study suggests that the translators may omit or supplement the stylistic features of the source text in the retranslation for readers' reception, which does not support the retranslation hypothesis. Finally, the study extends our knowledge about the causes of retranslation. Apart from concerns about change, novelty, or the aging of previous versions, the translators attempted to bring historiography to wider readership as mass culture around the world. As a result, the translators endeavored to popularize the work to a wider readership with literariness and a reader-friendly format in order to promote early Chinese history from periphery to centrality, from margin to mainstream. 
Although the current study is based on paratextual analysis, the findings suggest that the translators' agency encompassing their motivation and the impact of their final products, the intertextual network constructed through the annotations, and the influence of history extend translation studies from the linguistic and textual levels to social-cultural and political contexts. Accordingly, the retranslations mirror the changing values in the diachronic development.

Finally, two limitations of this study need to be acknowledged. Firstly, it is worth mentioning that the current study has only examined (re)translation of historiography from the three perspectives reframed by Venuti on the basis of paratextual analysis because of the explanatory function of paratexts. Second, since the latest version of Zuozhuan was translated by three translators, it is impractical to identify the motivation and the influence of each translator; therefore, this study regards this version as a collaborative work. It is recommended that future research be undertaken in the areas of textual analysis and the diachronic study of the interpretation of key words, which may advance our understanding of the translation of historiography. 


\section{References}

AsiaNow. 2018. "AsiaNow Speaks with the Translators of Zuo Tradition/Zuozhuan.” May 1. Accessed March 11, 2020. https://www.asianstudies.org/asianow-speaks-with-thetranslators-of-zuo-traditionzuozhuan/.

Austin, John L. 1962. How to Do Things with Words. London: Oxford University Press.

Balcom, John. 2005. “An Interview with Burton Watson.” Translation Review 70 (1): 7-12. doi:10.1080/07374836.2005.10523916.

Bensimon, Paul. 1990. "Présentation." [Presentation.] Palimpsestes, no. 4, ix-xiii. https://journals.openedition.org/palimpsestes/598.

Berman, Antoine. 1990. "La retraduction comme espace de traduction." [Retranslation as a translation space.] Palimpsestes, no. 4, 1-7. doi:10.4000/palimpsestes.596.

Brooks, A. Taeko. 2003. "Heaven, $L i$, and the Formation of the Zuozhuan 左傳." Oriens Extremus 44 (2003/04): 51-100. https://www.jstor.org/stable/24047568.

Brownlie, Siobhan. 2006. "Narrative Theory and Retranslation Theory." Across Languages and Cultures 7 (2): 145-170. doi:10.1556/Acr.7.2006.2.1.

Bywood, Lindsay. 2019. "Testing the Retranslation Hypothesis for Audiovisual Translation: The Films of Volker Schlöndorff Subtitled into English.” Perspectives 27 (6): 815-832. doi:10.1080/0907676X.2019.1593467.

Deane-Cox, Sharon. 2014. Retranslation: Translation, Literature and Reinterpretation. London: Bloomsbury Academic.

Desmidt, Isabelle. 2009. “(Re)translation Revisited.” Meta 54 (4): 669-683. doi:10.7202/038898ar.

Di Giovanni, Elena. 2017. "New Imperialism in (Re)translation: Disney in the Arab World." Perspectives 25 (1): 4-17. doi:10.1080/0907676X.2016.1234490.

Durrant, Stephen. 1992. "Smoothing Edges and Filling Gaps: Tso Chuan and the 'General Reader."' Journal of the American Oriental Society 112 (1): 36-41. doi:10.2307/604583. 
transLogos 2020 Vol 3 Issue 1

Tao, Yuan, pp. 1-23

A Translation Studies Journal

From Margin to Mainstream:

Retranslation of Early Chinese History

(C) Diye Global Communications diye.com.tr|diye@diye.com.tr

Durrant, Stephen, Wai-yee Li, and David Schaberg, trans. 2016. Zuo Tradition/Zuozhuan: Commentary on the "Spring and Autumn Annals." By Zuo Qiuming. 3 vols. Seattle: University of Washington Press.

Garnaut, Ross. 2012. “China: New Engine of World Growth.” In China: New Engine of World Growth, edited by Ross Garnaut and Ligang Song, 1-18. Canberra: Asia Pacific.

Genette, Gérard. 1997. Paratexts: Thresholds of Interpretation. Translated by Jane E. Lewin. Cambridge: Cambridge University Press.

Giddens, Anthony. 1986. The Constitution of Society: Outline of the Theory of Structuration. Cambridge: Polity.

Girardot, Norman J. 2002. The Victorian Translation of China: James Legge's Oriental Pilgrimage. Berkeley: University of California Press.

Greenall, Annjo K. 2015. “Translators' Voices in Norwegian Retranslations of Bob Dylan's Songs." In "Voice in Retranslation," edited by Cecilia Alvstad and Alexandra Assis Rosa. Special Issue, Target 27 (1): 40-57. doi:10.1075/target.27.1.02gre.

Koskinen, Kaisa, and Outi Paloposki. 2015. "Anxieties of Influence: The Voice of the First Translator in Retranslation." In "Voice in Retranslation," edited by Cecilia Alvstad and Alexandra Assis Rosa. Special Issue, Target 27 (1): 25-39. doi:10.1075/target.27.1.01kos.

Kovala, Urpo. 1996. "Translations, Paratextual Mediation, and Ideological Closure." Target 8 (1): 119-147. doi:10.1075/target.8.1.07kov.

Kujamäki, Pekka. 2001. "Finnish Comet in German Skies: Translation, Retranslation and Norms." Target 13 (1): 45-70. doi:10.1075/target.13.1.04kuj.

Legge, Helen Edith. 1905. James Legge: Missionary and Scholar. London: The Religious Tract Society.

Legge, James, trans. (1872) 1991. The Chinese Classics. Vol. 5, The Ch'un Ts'ew with the Tso Chuen. By Zuo Qiuming. Hong Kong: Hong Kong Printing Office. Reprint, Taipei: SMC. Citations refer to the SMC edition.

Li, Wai-yee. 2014. "Poetry and Diplomacy in the Zuozhuan." Journal of Chinese Literature and Culture 1 (1-2): 241-261. doi:10.1215/23290048-2749431. 
transLogos 2020 Vol 3 Issue 1

Tao, Yuan, pp. 1-23

A Translation Studies Journal

From Margin to Mainstream:

Retranslation of Early Chinese History

(C) Diye Global Communications diye.com.tr|diye@diye.com.tr

Meschonnic, Henri. 2011. Ethics and Politics of Translating. Translated and edited by PierPascale Boulanger. Amsterdam: John Benjamins.

Pellatt, Valerie. 2013. "Introduction." In Text, Extratext, Metatext and Paratext in Translation, edited by Valerie Pellatt, 1-6. Newcastle upon Tyne: Cambridge Scholars.

Pines, Yuri. 2002. Foundations of Confucian Thought: Intellectual Life in the Chunqiu Period, 722-453 B.C.E. Honolulu: University of Hawai'i Press.

2017. "History without Anecdotes: Between the Zuozhuan and the Xinian Manuscript." In Between History and Philosophy: Anecdotes in Early China, edited by Paul van Els and Sarah A. Queen, 263-299. New York: State University of New York Press.

Rosenthal, Jesse. 2017. Good Form: The Ethical Experience of the Victorian Novel. Princeton: Princeton University Press.

Schaberg, David. 2002. A Patterned Past: Form and Thought in Early Chinese Historiography. Cambridge: Harvard University Asia Center.

Van Poucke, Piet. 2017. "Aging as a Motive for Literary Retranslation: A Survey of Case Studies on Retranslation." Translation and Interpreting Studies 12 (1): 91-115. doi:10.1075/tis.12.1.05van.

Venuti, Lawrence. (2003) 2013. "Retranslations: The Creation of Value." Chap. 5 in Translation Changes Everything: Theory and Practice. London: Routledge.

Wang, John C. Y. 1977. "Early Chinese Narrative: The Tso-Chuan as Example." In Chinese Narrative: Critical and Theoretical Essays, edited by Andrew H. Plaks, 3-20. Princeton: Princeton University Press.

Watson, Burton, trans. 1989. The Tso Chuan: Selections from China's Oldest Narrative History. By Zuo Qiuming. New York: Columbia University Press.

Zhang, Huanyao, and Huijuan Ma. 2018. "Intertextuality in Retranslation." Perspectives 26 (4): 576-592. doi:10.1080/0907676X.2018.1448875. 